\title{
EDITORIAL
}

\section{The History of Cardiac Services and the Establishment of a Dedicated Cardiac Centre in the Kingdom of Bahrain}

\author{
Resan H Al-Badran ${ }^{1^{*}}$ \\ ${ }^{1}$ Director, Mohammed Bin Khalifa Bin Salman Al Khalifa Cardiac Centre, Bahrain. \\ *Corresponding author:
}

Dr. Resan H Al-Badran FRCP (Lond), FRCP(Edin), FRCP (Glasg.), Director, Mohammed Bin Khalifa Bin Salman Al Khalifa Cardiac Centre, Bahrain. Tel: + (973) 17889997. E-mail: Afernandes@mkcc.bh

Received date: June 19, 2021; Accepted date: July 25, 2021; Published date: December 31, 2021

\section{History}

The Bahrain Defence Force Royal Medical Services (BDFMS) was established in 1968. It was a subunit of the Ministry of Defence (called the National Guard). At that time the Overseas Treatment Committee of the Ministry of Health were referring more than 300 Bahraini cardiac patients annually to overseas centres for investigation and management of their cardiac diseases. This overseas treatment had many drawbacks; delays when urgent or emergency intervention was needed, open ended expenses, inconvenience, lack of family support etc., Bahrain entered the 1990's devoid of an interventional cardiology or cardiac surgery facility which would attest to the high standards of the noninvasive cardiac services that managed complex cardiac pathologies.

With the rising incidence of cardiac diseases in Bahrain (especially ischemic heart disease and congenital heart diseases) it was predicted that in the absence of a local dedicated cardiac centre there would be an enormous rise in the number of patients being referred overseas (together with overall cost) but more importantly the potential for several avoidable fatalities before such arrangements could be made. This scenario was clearly not sustainable, and it was the driving force behind the decision to establish a dedicated cardiac centre in Bahrain.
In early 1992 the BDFMS unit moved to the current "new" BDF hospital with a vast expansion of services. This included the establishment of a specialised cardiac centre that was named the Mohammed bin Khalifa bin Salman Cardiac Centre (MKCC) which opened in October 1992 under the vision and directorship of Dr Resan Al Badran (Figure 1).

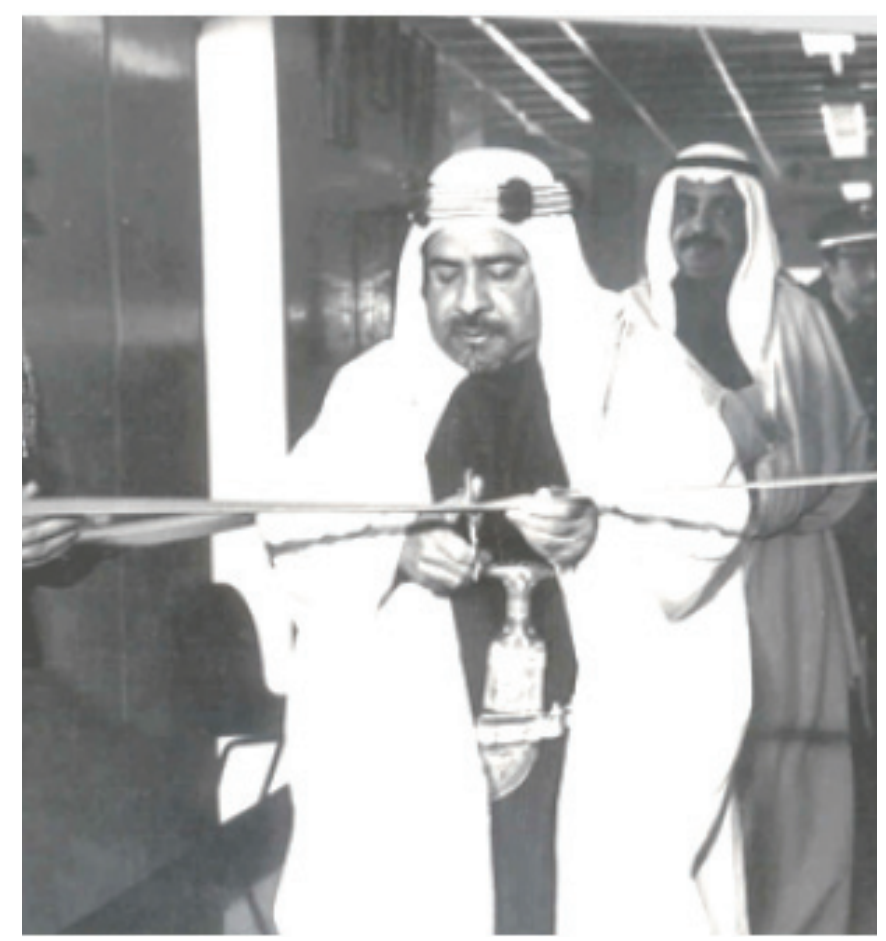

Figure 1: His Royal Highness the Emir Isa Bin Salman Al Khalifa at opening of new BDF Hospital 1992 
It was made available to all the population of Bahrain with all forms of investigative and therapeutic cardiology, followed shortly by cardiac surgery. Although overseas treatment at the expense of the State of Bahrain was only available to Bahraini nationals, the MKCC treatment was initially free of charge to the whole population of Bahrain. In this respect the Government of Bahrain demonstrated generous compassion to its large expatriate work force. Physical resources and manpower of the MKCC on opening in 1992 are presented in Table 1 and Table 2 respectively.

Table 1: Resources at MKCC during 1992

\begin{tabular}{|c|c|}
\hline Resource & Function \\
\hline Cardiac & Invasive investigation/intervention. \\
\hline Catheter & Cine angiography and angioplasty \\
\hline \multicolumn{2}{|l|}{ Laboratory } \\
\hline Coronary Care & Six cubicalised fully monitored \\
\hline Unit (CCU) & $\begin{array}{l}\text { beds for acute cardiology and post } \\
\text { angioplasty patients }\end{array}$ \\
\hline Cardiac & One fully equipped theatre \\
\hline \multicolumn{2}{|l|}{ Operating } \\
\hline \multicolumn{2}{|l|}{ Room } \\
\hline Cardiac & Four fully monitored beds \\
\hline Intensive Care & (two cubicalised) for post-cardiac \\
\hline \multirow[t]{2}{*}{ Unit (CICU) } & surgery patients and medical \\
\hline & patients requiring ventilation \\
\hline Cardiac Ward & Thirty beds for pre and post \\
\hline \multirow[t]{3}{*}{ (Ward 33) } & procedure cardiology cardiac \\
\hline & surgery patients and thoracic and \\
\hline & vascular surgery patients \\
\hline Cardiac & Four consulting rooms, dressing \\
\hline Outpatient & room, Electrocardiogram (ECG) \\
\hline $\begin{array}{l}\text { Department } \\
(\mathrm{COPD})\end{array}$ & room \\
\hline Diagnostic and & Two Echo Doppler machines, 1 \\
\hline Investigation & exercise test, 24-hour Holter and \\
\hline \multirow[t]{2}{*}{ Laboratory } & blood pressure monitoring \\
\hline & equipment \\
\hline
\end{tabular}

Table 2: Human resource at MKCC in 1992

\begin{tabular}{|c|c|}
\hline Resource & Function \\
\hline \multirow[t]{3}{*}{ Cardiology } & 4 consultants \\
\hline & 4 residents \\
\hline & 7 technicians \\
\hline \multirow[t]{2}{*}{ Cardiac surgery } & 2 consultants \\
\hline & 2 residents \\
\hline \multirow[t]{3}{*}{ Cardiac Anaesthesia } & 2 consultants \\
\hline & 1 senior technician \\
\hline & 1 trainee technician \\
\hline Clinical Perfusion & 2 clinical perfusionists \\
\hline \multirow[t]{7}{*}{ Nursing } & $\begin{array}{l}\text { a) } 1 \text { principal nursing officer } \\
\text { (PNO)/ } 3 \text { nursing officers }\end{array}$ \\
\hline & $\begin{array}{l}\text { b) Theatre: } 1 \text { head nurse/ } 6 \\
\text { staff nurses }\end{array}$ \\
\hline & $\begin{array}{l}\text { c) Catheter Laboratory: } 1 \\
\text { head nurse/3 staff nurses }\end{array}$ \\
\hline & $\begin{array}{l}\text { d) Cardiac Intensive Care } \\
\text { Unit (CICU): } 1 \text { head } \\
\text { nurse/16 staff nurses }\end{array}$ \\
\hline & $\begin{array}{l}\text { e) Coronary Care Unit } \\
\text { (CCU): } 1 \text { head nurse/15 } \\
\text { staff nurses }\end{array}$ \\
\hline & $\begin{array}{l}\text { f) Ward 33: } 1 \text { head nurse/ } \\
23 \text { staff nurses }\end{array}$ \\
\hline & $\begin{array}{l}\text { g) Cardiac Outpatient } \\
\text { Department (COPD): } 1 \\
\text { head nurse/2 staff nurses }\end{array}$ \\
\hline Community care & 2 nurses \\
\hline Cardiac technicians & 3 technicians \\
\hline Physiotherapy & 3 physiotherapists \\
\hline Dietetics & 1 dietician \\
\hline Clerical & 6 clerks \\
\hline Secretarial & 5 secretaries \\
\hline \multirow[t]{2}{*}{ Administration } & Cardiac Centre Director \\
\hline & 1 administrator \\
\hline
\end{tabular}




\section{Services provided in 1992}

Cardiology outpatients were held 4 days per week and cardiac surgery once per week. In addition, a monthly paediatrics/cardiac surgery combined clinic where paediatric patients both medical and post operative were seen. Two anticoagulant (AC) clinics were also held each week, one for medical patients and one for surgical valve replacement patients.

In the first two years after opening the MKCC undertook approximately six times the expected investigative workload and three times the predicted number of open-heart surgeries. Many thoracic, vascular surgeries and closed heart surgeries and pacemaker implantation procedures were also performed.

\section{Status}

From 1992 till currently the MKCC has continued to provide a comprehensive range of cardiac services by a team of highly qualified, experienced professionals in the most leading-edge techniques of cardiology today. This cardiac care ranges from treatment, diagnosis, and prevention to research and education. The centre continued to grow by serving both adult and pediatric patients with the full range of diagnostic and interventional techniques. By 2019 the numbers have increased dramatically (Table 3).

Table 3: Statistics comparison of patient cases

\begin{tabular}{lcc}
\hline Area & $\mathbf{1 9 9 2}$ & $\mathbf{2 0 1 9}$ \\
\hline Surgical cases & & 428 \\
Cath Lab cases & & 2589 \\
CCU (cardiac ICU) & & 1646 \\
Cardiac Ward Admissions & & 4094 \\
CPC (chest pain clinic visits) & N/A & 14248 \\
& & $>14000$ \\
AC (anticoagulation clinic & N/A & 9619 \\
visits) & & \\
Diagnostic (non-catheter) & & 19041 \\
tests & & \\
Nursing Staff & 77 & 336 \\
Doctors & 14 & 58 \\
Paramedical/technical staff & 7 & 30 \\
Administrative staff & 12 & 30 \\
\hline
\end{tabular}

The "New" MKCC Cardiac Centre
With this exponential growth and expansion, it became clear that a new cardiac centre dedicated to the prevention, investigation, and treatment of cardiac disease for all ages was required as part of the major efforts to upgrade Bahrain's medical infrastructure. A single centre design that offers the patients and families streamlined cardiologyconcentrated services under one roof was proposed by the Director of the MKCC (Dr Resan Al Badran) in 2005. The Prime Minister Prince Khalifa bin Salman Al Khalifa was fully supportive of the endeavour and endorsed the project. The project was well planned. It would be the country's most comprehensive, state-of-the-art cardiac unit carefully designed after studying designs of similar units globally to appreciate current and future requirements of a cardiac centre.

A site adjacent to the existing Awali Hospital was identified and the foundation stone laid by His Royal Highness Prime Minister Prince Khalifa bin Salman Al Khalifa on June 10, 2015 (Figure 2).

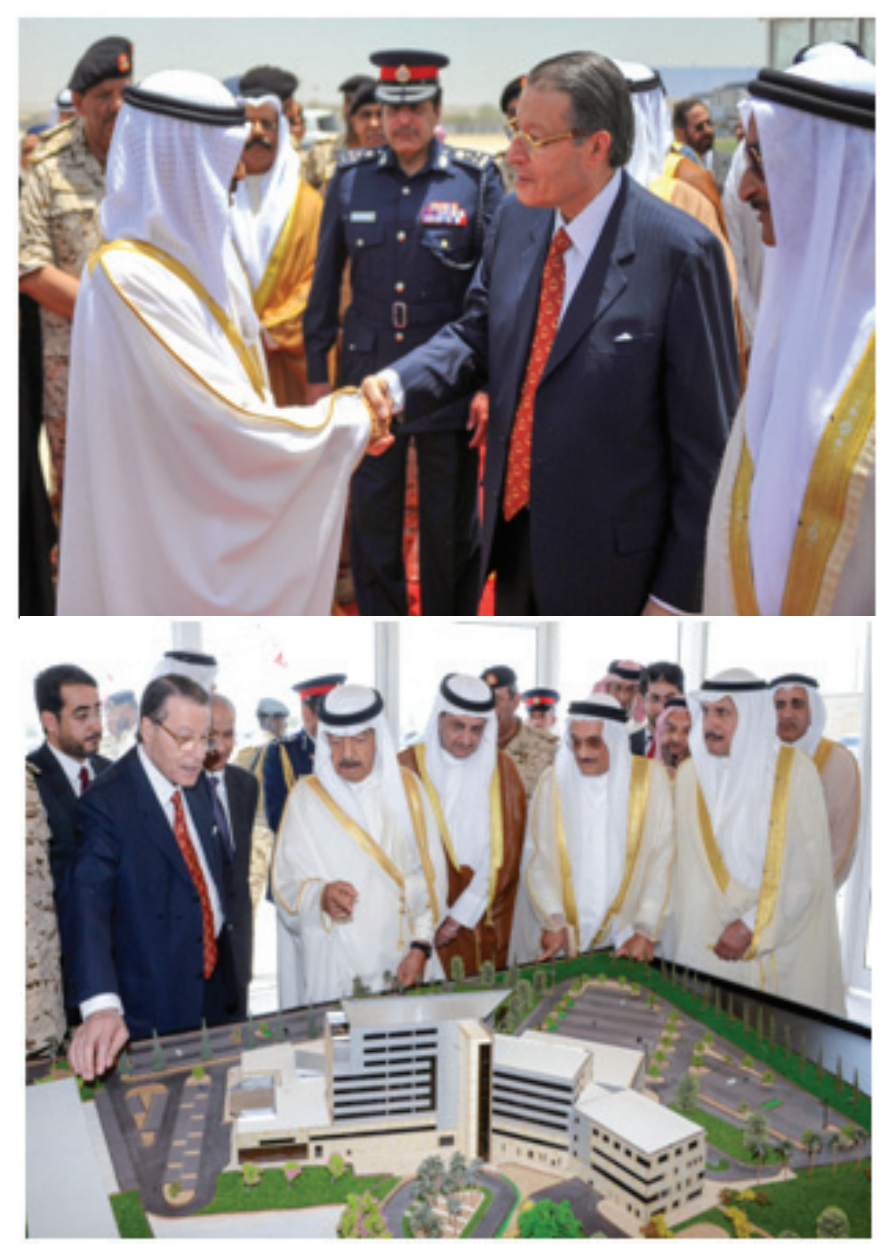

Figure 2: His Royal Highness Prime Minister Prince Khalifa bin Salman Al Khalif and Dr Resan $\mathrm{H} \mathrm{Al}$ Badran at the laying of the foundation stone for the new MKCC in 2015 
The facilities at the new centre have been specifically designed by the medical staff to provide the exceptional and world class standards to our patients and their families. All diagnostic, treatment and recovery areas are contiguous, spacious, and modern with the latest equipment necessary to care for all. Once operational the facility will have 148 beds (up from the existing 68 beds). This includes two Royal suites, and four very important person (VIP) rooms would also be available to serve our elite clientele` (Figure 3).

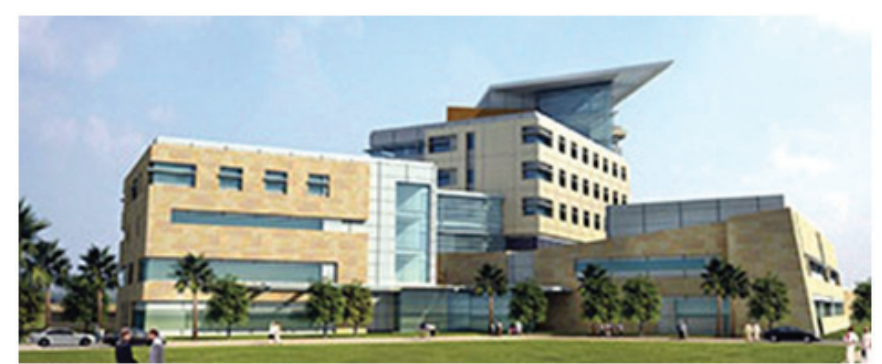

Figure 3: Computerised Model of the new MKCC in Awali
The Centre will offer a full range of diagnostic and treatment services for adults, teenagers, children, and infants with acquired and congenital heart disease with the latest minimal interventional catheter cardiology procedures as well as closed and open-heart surgery from the common to the extremely complex. Furthermore, the centre will continue to provide a 24-hour cardiology service and emergency angioplasty for treatment of acute myocardial infarction patients. All the services will continue to be free of charge to all Bahraini nationals. 